\title{
MUDANÇA DAS PRÁTICAS SÓCIO-EDUCATIVAS NA FEBEM-SP: AS REPRESENTAÇÕES SOCIAIS DE FUNCIONÁRIOS
}

\author{
Rita de Cássia Pereira Lima \\ Centro Universitário Moura Lacerda (CUML) - Ribeirão Preto/SP
}

RESUMO: O objetivo da pesquisa é analisar as representações sociais da mudança de práticas sócio-educativas entre funcionários da Fundação Estadual do Bem-Estar do Menor de São Paulo (FEBEM-SP). Fundamenta-se na teoria moscoviciana das representações sociais. A "mudança" foi contextualizada com base na Psicologia das Minorias Ativas. Foram realizadas entrevistas semi-estruturadas com 15 funcionários de uma unidade que se propunha a erradicar qualquer tipo de violência física contra o adolescente ator de ato infracional. A Análise de Conteúdo Temática identificou três temas-chave: "A proposta", "FEBEM-SP" e "Mudança". O núcleo figurativo da representação social da mudança situa-se em torno da violência física. Se compactuarem com esse tipo de violência, os profissionais contribuem para a consolidação dos métodos tradicionais da instituição. Negá-la significa romper e buscar práticas sócio-educativas mais humanistas, nem sempre vistas como possíveis. Representações sociais arcaicas veiculadas na instituição, fundadas na punição e na violência, dificultam a mudança de suas práticas sócio-educativas.

PALAVRAS-CHAVE: representações sociais; FEBEM; mudança.

\section{CHANGE OF SOCIAL-EDUCATIONAL PRACTICES IN FEBEM-SP: THE SOCIAL REPRESENTATIONS OF PROFESSIONALS}

\begin{abstract}
The objective of this research is to analyze social representations of change in socio-educational practices among professionals of FEBEM in São Paulo. The work is based in Moscovician theory of social representation. The "change" is based on Psychology of the Active Minorities. Interviews were conducted with 15 professionals of a unit in the Complex of Tatuapé, where any kind of physical violence against the delinquent adolescent is forbidden. The Thematic Analysis of Content identified three keythemes in the discourses: "Proposal", "FEBEM-SP" and "Change". The nucleus of the social representation of change is located around physical violence. If professionals agree with that kind of violence, they will contribute to the consolidation of the traditional approaches of the institution. Opposing it means working for ruptures and seeking more humanist social-educational practices, not always seen as possible. Archaic social representations present in the institution, founded upon punishment and violence, complicate the change of its social-educational practices.
\end{abstract}

KEYWORDS: social representations; FEBEM; change.

A pesquisa tem como objetivo estudar as representações sociais de funcionários quanto à mudança das práticas sócio-educativas na Fundação Estadual do Bem-Estar do Menor de São Paulo (FEBEM-SP). Esta instituição foi criada no Estado de São Paulo em 1976, sob a égide do governo militar, para atender crianças e adolescentes considerados "abandonados", "infratores" e aqueles cujas famílias, temporariamente, não tinham condições de mantê-los.

Desde sua criação, a FEBEM-SP é alvo de críticas por parte de diversos segmentos, sobretudo a imprensa, devido a seus métodos coercitivos e punitivos. Na década de 1970, a frequiência de crianças e adolescentes nas ruas já traduzia uma grave problemática sócio-econômica e o controle policial e institucional desses indivíduos preocupava algumas esferas da sociedade.

Mesmo com a redemocratização do país, no início na década de 1980, a instituição continuou sendo denunciada (por exemplo, pela Pastoral do Menor da Arquidiocese de São Paulo) devido aos castigos e violências contra o jovem. Esta situação persistiu com a Constituição de 1988 (Brasil,
1988), primeiro texto constitucional que fixa dispositivos que garantem direitos a crianças e adolescentes (Lima, 1994).

As revisões constitucionais inspiraram um movimento para substituir o Código de Menores de 1979 que envolveu, principalmente, o Ministério Público e Organizações NãoGovernamentais de Defesa da Criança e do Adolescente. Após discussões em âmbito nacional, esse projeto inicial resultou no Estatuto da Criança e do Adolescente - ECA (Brasil, Lei 8.069 de 13 de julho de 1990).

Em sua proposta de ruptura com o passado, o ECA tenta garantir direitos fundamentais a crianças e adolescentes, especialmente os de classes desfavorecidas que são expostos às mais diferentes formas de violência em seu cotidiano. Apesar desse dispositivo legal, até os dias atuais são veiculadas pela mídia notícias de chacinas envolvendo crianças e adolescentes, especialmente em São Paulo e Rio de Janeiro, além de rebeliões na FEBEM-SP provocadas por espancamento dos jovens. Ou seja, diversas formas de violência física contra crianças e adolescentes de classes sociais desfavorecidas persistem, mesmo em um regime democrá- 
tico legitimado por leis destinadas a protegê-los. Nota-se uma certa fragilidade no respeito à lei quando as pessoas não mudam sua maneira de pensar e agir.

O trabalho aqui apresentado insere-se neste contexto social. O estudo foi realizado com base na proposta de um diretor de unidade da FEBEM-SP, antigo funcionário conhecido por seu posicionamento contrário ao atendimento punitivo prestado pela instituição. Sob sua direção, qualquer tipo de violência física contra o jovem passou a não ser permitida, na tentativa de corresponder minimamente ao que está previsto no ECA.

Essa proposta foi implementada entre julho de $1997 \mathrm{e}$ fevereiro de 1999, em duas das 15 unidades que, na época, faziam parte do Complexo do Tatuapé (conhecido como Quadrilátero), situado na cidade de São Paulo. O trabalho na primeira unidade ocorreu entre julho/1997 e maio/1998. Na segunda, foi implementado no período de maio de 1998 a fevereiro de 1999. Ambas atendiam adolescentes do sexo masculino, de 14 a 18 anos, atores de atos infracionais considerados "graves" (de roubo a latrocínio).

A pesquisa buscou investigar, com base no olhar dos funcionários, como estava acontecendo esse processo de mudança em uma unidade inserida dentro de uma instituição que, no geral, silencia os atos de violência cometidos contra ojovem. Algumas questões atravessam o texto: Como os profissionais pensam a mudança na instituição? Quais são as dificuldades para se erradicar a violência física? Como mudar as práticas institucionais na FEBEM-SP, historicamente fundadas na punição e na violência?

Alguns comentários sobre a proposta tornam-se relevantes aqui. De imediato, foram rompidos procedimentos ditos "de segurança", exercidos no cotidiano da unidade. Por exemplo, os jovens eram obrigados a permanecer sentados no pátio por horas seguidas. Só podiam se locomover levantando a mão e perguntando em voz alta "com licença, senhor", sendo que nem sempre obtinham autorização. O jovem também deveria andar sempre com as mãos para trás, seja para conversar com um profissional ou para se locomover. Caso desobedecesse, poderia sofrer violência física.

Essas práticas foram abolidas. Conforme já mencionado, a nova proposta proibiu qualquer tipo de violência física contra o adolescente, que poderia circular livremente em espaços como o pátio. Somente o diálogo deveria ser utilizado para a resolução de conflitos. O diretor tentou agrupar pessoas que compartilhassem suas idéias, mesmo sem abertura para discutí-las com outras esferas de poder institucional. Embora o trabalho tenha sido realizado no interior de uma unidade, havia a intenção de provocar discussões, mobilização e adesão de uma maioria na instituição. Porém, este percurso foi extremamente árduo.

Na transferência do projeto, da primeira unidade para a segunda, os entraves se acumularam. Por exemplo, o di- retor pretendia ocupar as 178 vagas gradativamente, para que jovens e funcionários pudessem se adaptar à proposta. No entanto, foi pressionado a lotar a unidade em caráter de urgência e preencher o quadro de funcionários de acordo com indicações da instituição.

Apesar das dificuldades, a proposta continuou pautada no respeito, no diálogo, e principalmente, na absoluta erradicação da violência física por parte de funcionário contra jovem. Foi privilegiado o trabalho com as famílias, os vínculos com o jovem dentro da unidade e a parceria com a comunidade.

Esse tipo de abordagem causou impacto no Quadrilátero. A mudança de uma prática já enraizada e legitimada pela instituição provocou críticas e oposição entre as várias unidades. Por um lado, alguns funcionários antigos resistiam em refletir e mudar suas práticas. Os novos, por sua vez, muitas vezes não se sentiam à vontade para expressar um posicionamento crítico face à instituição.

Embora a resistência à mudança seja reforçada no universo institucional, é fundamental ressaltar a importância do trabalho de pequenos grupos que acreditam em outras possibilidades, mesmo que os resultados não sejam visíveis em curto prazo. É compreensível o desgaste de alguns funcionários, porém a FEBEM persiste, dentro de uma perspectiva de violência. Daí permanecem as questões: Como mudar a instituição, ou contribuir para o seu fim, começando, ao menos, pela erradicação da violência física? Um outro tipo de atendimento seria possível se as pessoas não mudarem seus valores pessoais e culturais? Qual é o papel dos funcionários nesse sentido?

A iniciativa aqui relatada permite refletir sobre essas questões. Embora o diretor não tenha dado continuidade à sua proposta (após um ano e meio foi transferido para uma unidade destinada a crianças e jovens "abandonados"), trata-se de um trabalho que provocou discussões entre funcionários, que causou desconforto para a instituição, que conseqüentemente deixou marcas.

A experiência incita reflexões teóricas. O processo de "mudança" pode ser analisado à luz de diferentes perspectivas: psicológica, psicanalítica ou sociológica. Neste trabalho será privilegiada sua dimensão psicossocial, considerando-se os aspectos individuais e sociais articulados em uma mesma realidade. Com este objetivo, a fundamentação da pesquisa pauta-se na Teoria das Representações Sociais (Moscovici, 1961) para compreender como os funcionários constroem idéias a respeito da "mudança" e na Psicologia das Minorias Ativas (Moscovici, 1976) para analisar o papel de grupos minoritários no enfrentamento desta questão social.

As representações sociais relacionam-se às mentalidades, às atitudes, às opiniões, às imagens que podem exercer uma ação para mudar condutas e comportamentos e possibilitar o questionamento e a transformação. 
Moscovici (1961) propôs a noção de representação social a partir da crítica ao conceito durkheimiano de "representações coletivas", aproximando-a e distinguindo-a de noções como mito, ideologia, visão de mundo, opinião, preconceito, imagem. $\mathrm{O}$ autor abriu um novo campo de estudos na Psicologia Social afirmando que as representações sociais ocupam uma posição "mista" porque estão situadas na encruzilhada de uma série de conceitos sociológicos e psicológicos. Ele enfatiza a necessidade de se fazer da representação "uma passarela entre o mundo individual e o mundo social" (Moscovici,1993, p.82).

De acordo com o autor, as representações sociais estão organizadas de maneira muito diversa segundo as classes, as culturas ou grupos e contribuem para os processos de formação de condutas e de orientação das comunicações sociais. Elas se formam principalmente quando as pessoas estão expostas às instituições, aos meios de comunicação de massa, à herança histórico-cultural da sociedade. São imagens que condensam um conjunto de significações, de sistemas de referências que permitem que se interprete os acontecimentos, que se dê sentido ao inesperado (Moscovici, 1978).

Segundo Jodelet (1993), a representação social é uma construção e expressão do sujeito, que pode ser considerado do ponto de vista epistêmico (aspectos cognitivos) ou psicodinâmico (mecanismos intrapsíquicos, motivacionais, etc.), mas também social ou coletivo (pertencimento e participações social e cultural).

A autora se refere às representações sociais como conhecimento "espontâneo", "ingênuo", chamado "conhecimento do senso comum", ou "pensamento natural", em oposição ao pensamento científico. Este conhecimento se constitui a partir das experiências, mas também de informações, saberes, modelos de pensamento recebidos e transmitidos pela tradição, educação, comunicação social. Tratase também de um conhecimento socialmente elaborado e partilhado (Jodelet, 1996). De acordo com Moscovici, “quando se estuda o senso comum, o conhecimento popular, nós estamos estudando algo que liga sociedade ou indivíduos, a sua cultura, sua linguagem, seu mundo familiar" (2003, p.322).

Para Sá (1996), as representações sociais são reconhecidas como fenômenos psicossociais histórica e culturalmente condicionados, sendo que sua explicação deve se dar aos níveis de análise posicional e ideológico. Na mesma direção, Bonardi e Roussiau (1999) afirmam que as dinâmicas social, técnica, ideológica e política agem sobre as concepções individuais:

o indivíduo personaliza os elementos (as idéias sociais) que circulam na sociedade. Ele constrói, ao mesmo tempo em que reconstrói para si mesmo, a representação de um objeto através do contato com seu ambiente. Ele ajusta/reajusta sua representação por meio de suas relações com os membros dos grupos aos quais ele pertence. Esse processo conduzirá então, não a uma representação individual, mas a uma representação social compartilhada. (p.18)

No que se refere aos profissionais da FEBEM-SP, é fundamental conhecer suas representações sobre a mudança porque elas orientam suas práticas. Esses profissionais têm seus próprios códigos de interpretação marcados principalmente pela cultura da instituição. No âmbito desse trabalho pretende-se verificar, por meio dessas representações, como um grupo específico vivenciou um processo de mudança. Devido à sua característica minoritária na instituição, adotou-se também, como referencial, a Psicologia das Minorias Ativas (Moscovici, 1976).

Moscovici chamou a atenção para a "Psicologia das Minorias Ativas" (1976) com o objetivo de compreender as relações de influência e os fenômenos de conformidade e de submissão às normas de certos grupos sociais. $\mathrm{O}$ autor partiu de uma crítica ao modelo tradicional relativo à mudança, em que a influência é considerada um processo unilateral que parte dos que ocupam uma posição dominante (maioria) em direção aos que estão em uma posição dominada (minoria).

Nessas condições, a mudança é vista como uma modificação das atitudes dos destinatários (minoria) sob a influência dos que constituem a fonte dessa mudança (maioria). Para Moscovici, a mudança deve ser considerada como um processo de influência recíproca entre os pólos majoritário e minoritário. Nesse processo de influência, o pólo minoritário, que no contexto social é o que tem reconhecimento e legitimidade somente através da submissão às normas, pode na realidade ser produtor de novas normas à sua maneira (Fischer, 1992).

Na perspectiva tradicional, o receptor seria um sujeito passivo. Moscovici (1996) afirma que os sujeitos podem ser ativos quando reagem às pressões e tentam impor seu ponto de vista. $\mathrm{O}$ autor questiona o papel exclusivo da maioria como fonte de influência e explica os fenômenos de mudança como resultado de uma influência minoritária. A minoria seria potencialmente portadora de mudança porque sua influência se manifesta na aparição de idéias novas ou na modificação de comportamentos existentes.

Para Moscovici, o estudo das minorias permite uma concepção da mudança social a partir de várias dimensões: o conflito, a importância das normas e das relações de poder, o lugar das minorias. As minorias constituem um instrumento de mudança social porque são sensíveis às idéias novas e contribuem para difundi-las. Porém, esse procedimento não é sempre bem-sucedido porque a inovação proposta freqüentemente interfere em outros fatores que podem bloquear a adesão daqueles a quem ela se direciona. De acordo com Fischer, "quando uma minoria procura influenciar a sociedade em relação a normas 
ou respostas muito fortemente interiorizadas, ela se choca com a maior resistência" (1992, p.82).

Entretanto, Moscovici afirma que esse conflito faz parte de toda mudança social: "a luta entre as forças de conformidade e as forças de inovação nunca perde seu atrativo e permanece decisiva tanto para uma quanto para a outra" (1996, p.10). As práticas e projetos originais de transformação das relações sociais devem se pautar nessa relação, motivando ações que permitam ao grupo minoritário prosseguir seus objetivos e transformar sua condição de acordo com seus recursos e valores.

Apesar das dificuldades e resistências encontradas, a proposta implementada na FEBEM-SP pode ser ilustrada pela colocação de Moscovici: "a tensão entre os que devem defender certas normas, opiniões ou valores e os que devem defender outras a fim de mudar essas normas, essas opiniões e esses valores é o resultado sob o qual repousa o crescimento de uma sociedade" (1996, p.14). Nesse sentido, acredita-se que o conflito minoria-maioria possa provocar mudanças na instituição, mesmo que seja a médio ou longo prazo.

\section{Método}

\section{Sujeitos, Material, Procedimentos}

A pesquisa de campo iniciou-se com duas entrevistas com o diretor para melhor conhecimento da proposta e viabilização do contato com outros profissionais, todos da segunda unidade em que o trabalho foi implementado.

O estabelecimento contava com 73 funcionários (um diretor, uma encarregada técnica, um encarregado administrativo, um psicólogo, quatro assistentes sociais, três auxiliares de escritório, dois auxiliares de serviço, 10 coordenadores de turno e 50 monitores) e atendia uma média de 176 adolescentes.

Foram entrevistados 15 profissionais: diretor (psicólogo, mestre em serviço social e doutorando em educação), encarregada técnica (assistente social), três assistentes sociais, cinco coordenadores de turno (um professor de educação física, um historiador, um pedagogo, um com superior completo - não declarou área -, um com superior incompleto-administração de empresas), quatro monitores (uma matemática, uma socióloga - uma com magistério e um com $2^{\circ}$ grau completo), um auxiliar de serviços exercendo a função de auxiliar de escritório ( $2^{\circ}$ grau completo).

As entrevistas foram semi-estruturadas e aleatórias tentando-se o contato com diferentes categorias profissionais. Só foram entrevistados aqueles que voluntariamente aceitaram participar da pesquisa.

O material foi analisado com base na análise de conteúdo (Bardin, 1986). Minayo (1996) menciona que a análise de conteúdo "parte de uma literatura de primeiro plano para atingir um nível mais aprofundado: aquele que ultra- passa os significados manifestos" (p.203). Para a autora, a análise de conteúdo relaciona estruturas semânticas (significantes) com estruturas sociológicas (significados) dos enunciados. A superfície dos textos descrita e analisada é articulada aos fatores que determinam suas características, como aspectos psicossociais, contexto cultural, contexto e processo de produção da mensagem.

Optou-se pela análise temática, modalidade da análise de conteúdo. De acordo com Minayo (1996), a noção de "tema" relaciona-se a uma afirmação a respeito de determinado assunto, comportando um feixe de relações e podendo ser apresentada através de uma palavra, uma frase, um resumo, entre outros. Para Bardin (1986), "fazer uma análise temática consiste em observar os "núcleos de sentido" que compõem a comunicação, e cuja presença ou frequiência de aparição poderão significar alguma coisa para o objetivo analítico escolhido" (p.105).

Dentro dessa perspectiva, três temas-chave foram identificados, inferindo-se categorias e sub-categorias para cada um. Os temas "A proposta", "FEBEM-SP" e "Mudança" foram considerados fundamentais, visto que estão estreitamente articulados e permitem analisar as representações sociais da mudança expressas nos discursos.

\section{Resultados e Discussão}

A Teoria das Representações Sociais foi retomada para a construção da análise. Moscovici (1978) colocou em evidência dois processos formadores das representações, sempre articulados: a objetivação e a ancoragem. Esses processos mostram a interdependência entre a atividade psicológica e suas condições sociais de exercício.

A objetivação seria a dimensão mais individual e cognitiva da representação. Define-se como uma operação imaginante e estruturante, ou seja, o sujeito faz corresponder coisas às palavras, transforma conceitos em imagens ou dá corpo a esquemas conceituais. A ancoragem seria a dimensão mais social da representação. Diz respeito ao enraizamento social da representação, à significação e utilidade que lhe são conferidas. Ela se refere também à integração cognitiva do objeto representado no sistema de pensamento pré-existente (Jodelet,1996). O "núcleo figurativo", conteúdo norteador de uma representação social, relaciona-se a esses dois processos.

As entrevistas mostraram que a representação da mudança tem como núcleo figurativo a "violência física" contra o adolescente, que denota a construção de duas imagens: a aprovação, em geral legitimada pela instituição, e a negação, tentando-se encontrar um saída mais humanista, fundamentada nos direitos fundamentais da criança e do adolescente (processo de objetivação).

A cada uma destas imagens correspondem interpretações, baseadas em conhecimentos prévios, base cultural, 
inserção social dos sujeitos, vivência na instituição, posicionamento crítico quanto à questão social dos adolescentes de classes desfavorecidas no Brasil. A aprovação da violência física está enraizada, principalmente, na antiga cultura escravagista do país que pune com castigos físicos os menos favorecidos socialmente. A abordagem "humanista" relaciona-se, sobretudo, a teorias educacionais e psicológicas contemporâneas e a direitos humanos e ideais democráticos que caracterizam alguns segmentos da atualidade, também expressos no ECA (processo de ancoragem).

Os três temas analisados - "Proposta", "FEBEM-SP", "Mudança" - e sua articulação ilustram esses aspectos.

\section{"A proposta"}

Seguindo os princípios da análise de conteúdo temática, foram inferidas categorias que expressam ênfase na erradicação da violência física. As bases da proposta (ações da unidade, posicionamento da FEBEM e das outras unidades, papel dos educadores, possibilidades de sucesso, pessimismo e necessidade de auto-crítica) se fundamentam neste aspecto.

A interdição da violência física é, de fato, percebida como a grande inovação. Porém, as possibilidades de sucesso são vislumbradas a longo prazo. Nos discursos abaixo, o primeiro confirma a ausência de violência física na unidade e o segundo se mostra pessimista quanto à continuidade da proposta:

...já tenho oito meses aqui e nunca teve caso de violência... nem de menino com funcionário, nem de funcionário com menino... (assistente social)

... a gente continua, mas na verdade existe uma pressão muito forte para que isso não leve muito tempo... existem reuniões de coordenadores, diretores, monitores pedindo para acabar com isso aqui... (coordenador de turno)

Percebe-se a ambigüidade entre a intenção de romper, de inovar, e as possibilidades de implementá-lo dentro da estrutura organizacional da instituição. Por exemplo:

...eu percebo uma discriminação dessa unidade... a maioria dos funcionários que a gente encontra de outras unidades... você percebe que são favoráveis à violência, né? Eles não acreditam nesse trabalho... percebo, no geral, um descrédito... (assistente social)

Várias ações da unidade são mencionadas: interlocução com famílias e comunidade, apoio psicossocial e qualificação do adolescente. Notou-se a preocupação em suscitar discussões, entre os funcionários, sobre temas sociais que afetam esses adolescentes e que reforçam sua situação de vulnerabilidade. $\mathrm{O}$ discurso abaixo aponta esse tipo de reflexão:

...é você acompanhar toda a exclusão... e, para mim, eles são excluídos da história, são excluídos de tudo, até das relações mesmo... e a unidade tenta resgatar isso... (monitora)

Nesse sentido, o papel dos educadores é considerado fundamental para a consolidação do trabalho, sendo mencionadas a necessidade de formação e envolvimento. Por exemplo:

... a gente vê hoje uma equipe um pouco mais madura... mas as situações difíceis surgem no dia-a-dia... a gente gostaria de ter uma unidade um pouco mais preparada para essa proposta... (encarregada técnica)

Muitos entraves são percebidos na implementação da proposta: os profissionais se sentem rejeitados e desrespeitados pelas outras unidades, citam a falta de apoio da instituição quanto a implementar mudanças, mencionam que recebem muitas críticas. Poucos discursos indicam o impacto positivo da proposta, destacando-se mais a curiosidade despertada no Quadrilátero. Nota-se a relevância da auto-crítica para que a proposta se desenvolva e, conseqüentemente, tenha visibilidade:

...se o menino não dá certo, a culpa também é nossa... porque ele veio para cá ficar com a gente e a gente tem que tentar passar o mínimo para esse jovem, né? (coordenador de turno).

No seu conjunto, esse tema mostrou que, apesar da intenção de mudança, as dificuldades de ruptura são grandes, sobretudo no âmbito institucional. A pressão sofrida por esse grupo minoritário revela a resistência da FEBEM-SP em romper com a violência física contra o adolescente ator de ato infracional, assunto abordado no tema seguinte.

\section{"FEBEM-SP"}

As categorias aqui inferidas também têm como centralidade a questão da violência, que se manifesta nas dificuldades para realização de um trabalho sócio-educativo e implementação de políticas de atendimento ao adolescente ator de ato infracional, além das más condições de atendimento das unidades.

A maioria expressa uma visão bastante crítica da instituição, onde não há proposta sócio-educativa. A problemática da violência perpassa esse tipo de discurso. Por exemplo:

...vai ter que chegar num momento que ela (a instituição) vai ter que se definir... se ela pune o jovem que cometeu ato infracional ou se ela educa esse jovem... porque fica um duelo muito grande entre educar $e$ punir... (coordenador de turno)

Escassez de funcionários (incluindo má formação dos mesmos), superlotação e espaço físico inadequado são freqüentemente mencionados. Fica evidente que a FEBEMSP não cumpre seu papel no sentido de respeitar os direitos do adolescente que atende e a quem deveria apontar um caminho para a abordagem de seus conflitos: 
...aqui a gente tem cento e oitenta meninos... cada técnico chega a ter quase cinqüenta... então, não dá para conversar sempre com eles, todos os dias... atender bem a família... então, isso é uma grande dificuldade... (assistente social)

A FEBEM-SP é vista como ineficaz e, mesmo assim, resistente a mudanças. A nucleação dos discursos em torno da "violência física" é fundamental para a compreensão das representações sociais da mudança, comentada a seguir.

\section{"Mudança"}

Nesse tema, percebe-se o papel da erradicação da violência física para que se possa vislumbrar um processo de mudança das práticas sócio-educativas na instituição. A postura dos entrevistados face à inovação, as dificuldades enfrentadas, a oposição sofrida por parte da FEBEM e manifestações afetivas revelam esse conteúdo norteador.

Apesar das dificuldades e resistências face ao novo, os discursos expressam o processo em que a nova proposta foi adquirindo significado para os entrevistados:

... a gente tem que aprender muito, tem que crescer muito... não sei se vamos ter tempo, mas é uma coisa que a gente tem que ter fôlego... porque é muito difícil para a gente lutar contra tudo isso... porque realmente é uma luta, é uma guerra... (coordenador de turno)

A maioria expressa mal-estar e sentimento de isolamento, observando-se fortemente a dimensão afetiva que se manifesta em um processo de mudança. Para os entrevistados, os interesses e valores da instituição prevalecem, influenciando o que pode ou deve ser desenvolvido em seu interior. Por exemplo:

...Isso é doloroso... Essa solidão é uma coisa muito
perigosa... porque eu sou uma pessoa... como eu disse
para você, eu sou um profissional, mas sou uma pes-
soa... ela mexe com limites pessoais... (diretor)

A FEBEM, enquanto estrutura político-social, é vista como a grande cerceadora de mudanças, exercendo influência na forma de pensar e agir de seus funcionários:

...todo processo de mudança é muito difícil... e eu tenho certeza que para todas as unidades, para quebrar um pouquinho essa coisa pesada da instituição total, tem que ter mudança de estrutura. (encarregada técnica)

Em alguns discursos, é clara a postura conservadora da instituição, fundada na punição e na violência. Para a maioria, essa situação dificulta ou impede a mudança de suas práticas sócio-educativas:

... a proposta trouxe uma discussão dentro do Quadrilátero que é a discussão da desestruturação das outras unidades, né? Todo mundo fala que ela atrapalha... mas por que ela atrapalha? Porque ela não bate... (coordenador de turno)
Esse tema, articulado aos dois anteriores, mostrou que os profissionais se sentem pressionados a se situar dentro de uma ambigüidade: compactuar com a violência física, contribuindo para a legitimação dos métodos tradicionais da instituição, ou negá-la, tentando rupturas e buscando práticas sócio-educativas mais humanistas, nem sempre vistas como possíveis. Foi dentro dessa contradição que eles participaram de uma proposta de mudança na FEBEMSP, tendo a oportunidade de refletir sobre seus valores e identidade profissional.

\section{Considerações Finais}

O trabalho procurou mostrar as possibilidades de mudança das práticas institucionais na FEBEM-SP com base nas representações sociais de funcionários, valorizando o papel das minorias enquanto grupos de pressão.

Apesar da minoria não ter resistido à pressão da maioria, a proposta aponta os entraves a serem enfrentados no trabalho sócio-educativo junto aos jovens atores de ato infracional. Os discursos mostraram a relação estreita entre erradicação da violência física e mudança das práticas na FEBEM-SP.

Percebe-se um longo caminho a percorrer, que pode começar com a mudança de representações. Acredita-se que a mudança das práticas institucionais pode ocorrer num plano microssocial, com grupos minoritários que se posicionem criticamente, façam auto-crítica sobre sua forma de pensar e agir e se contraponham à maioria. A experiência aqui relatada é instigante quanto a refletir sobre a influência das minorias quando uma mudança social é pretendida, incluindo, conseqüentemente, as representações sociais dos sujeitos envolvidos.

\section{Referências}

Bardin, L. (1986). L'analyse de contenu. Paris: PUF.

Bonardi, C., Roussiau, N. (1999). Les représentations sociales. Paris: Dunod.

Brasil (1988). Constituição: República Federativa do Brasil. Brasília: Senado Federal/Centro Gráfico.

Brasil (1990). Lei $n^{o} .8069$ de 13 de julho de 1990-dispõe sobre o Estatuto da Criança e do Adolescente (ECA). Brasília: Palácio do Planalto.

Fischer, G.-N. (1992). La dynamique du social: violence, pouvoir, changement. Paris: Dunod.

Jodelet, D. (1989). Représentations sociales: un domaine en expansion. In: Jodelet (Eds.) Les représentations socials (pp.31-61). Paris: PUF.

Jodelet, D. (1996). Représentations Sociale: phénomènes, concept et théorie. In: Moscovici, S. (Ed.) Psychologie Sociale (pp.357378). Paris: PUF.

Lima, R.C.P. (1994). Le processus d'élaboration de diagnostics sur les enfants et adolescents "abandonnés", "assistés" et "infracteurs" par les equipes interdisciplinaires de la Fondation de l'Etat du 
Lima, R.C.P. "Mudança das Práticas Socio-Educativas na FEBEM-SP: as Representações Sociais de Funcionários"

Bien-Être du Mineur de São Paulo (FEBEM-SP)-Brésil. Tese de Doutorado não-publicado, Université René Descartes, Paris V.

Minayo, M.C.S. (1996). O desafio do conhecimento-pesquisa qualitativa em saúde. São Paulo, Rio de Janeiro: Hucitec-Abrasco.

Moscovici, S. (1961). La psychanalyse, son image et son public. Paris: PUF.

Mosocovici, S. (1978). A Representação Social da Psicanálise. Rio de Janeiro: Zahar.

Moscovici, S. (1976). Social Influence and Social Change. Londres: Academic Press.

Moscovici, S. (1996). Psychologie des minorités actives. Paris: PUF.

Moscovici, S. (1993). Des représentations collectives aux représentations sociales. In: Jodelet, D. (Ed.) Les représentations socials (pp.62-86). Paris: PUF.

Moscovici, S. (2003). Representações Sociais - Investigações em Psicologia Social. Petrópolis: Vozes.

Sá, C.P. (1996). Núcleo Central das Representações Sociais. Petrópolis: Vozes.

Rita de Cássia Pereira Lima é Professora no Programa de Pós-Graduação em Educação Mestrado, Centro Universitário Moura Lacerda (CUML), Ribeirão Preto, SP. Endereço para correspondência com a autora: Rua Sete de Setembro, 1755, 14025 200, Ribeirão Preto, SP. ritalima@netsite.com.br
Trabalho desenvolvido no Programa de Pós-Graduação em Serviço Social da Pontifícia Universidade Católica de São Paulo com apoio do CNPq - Bolsa Recém-Doutor.

\section{Mudança das práticas sócio-educativas na FEBEM-SP: as representações sociais de funcionários}

Rita de Cássia Pereira Lima

Recebido: 03/11/2005

$1^{a}$ revisão: 09/01/2006

Aceite final: 15/02/2006 